receive the full benefit of purchasing their warservice years it should not demand full payment of the relevant contributions. Yet it is demanding full payment, with compound interest not only to the date of retirement but also up to 1975,10 or more years after retirement.

Can nothing be done to rectify the blatant inequity with which elderly retired doctors are being treated?

ROBERT V GOODLIFFE

Uckfield, Sussex

\section{Consultants' work to rule}

SIR,-I wish to join Dr D F Rees (16 September, $p$ 835) in protesting against the statement by a Government spokesman quoted by Scrutator (12 August, p 511) that consultants worked "to rule" for eight months in 1976.

There was a work to contract by consultants when the consultant anaesthetists in the South Tees Health District endeavoured to support their colleagues in other specialties in this exercise, during which time we interpreted our contracts in a manner virtually identical with that independently and at the same time recommended by Barbara Castle, but many of us found that it was necessary for us to continue providing (as we did) extracontractual services gratuitously for the benefit of our patients.

Much was then said, and is still being said, in the press about an alleged work to rule or a work to a restrictive code. Apart from consideration for one's patients the major impediment which I would find in such an exercise would be the absence of any book of rules to which to work. Does anyone have a rule book for consultants?

Harold G SAUnders

Department of Anaesthesia,

West Lane Hospital,

Middlesbrough, Cleveland

\section{General practice records}

SIR,-I was disappointed to see the question of the value of A4 records raised in your columns once again.

Those of us who have been involved in thinking about computerised record systems in general practice over the past few years, have come to the conclusion that the ultimate future of the practice record lies in computerisation, probably using microcomputers, which are just beginning to be developed. I would go so far as to say that anybody who has not yet amended their practice to A4 records or become involved in the cost of them has missed the boat and would be better advised to wait for the next step, which will be a computerised system solving all the storage problems created by $\mathrm{A} 4$ records.

K J BOLDEN

Department of General Practice,

University of Exeter Postgraduate Medical Institute,

\section{Royal Medical Benevolent Fund Christmas Appeal}

SIR,-Last year both our members and the medical profession in general responded magnificently to my Christmas appeal and the record sum of $£ 18189$ was contributed. In consequence we were able to send a worthwhile gift to every one of our beneficiaries to help them, especially the children, to enjoy a Christmas free from want.

I am sure that readers will know that the Royal Medical Benevolent Fund is a charity supported solely by doctors for the benefit of doctors and their dependants. We trust that the medical profession will continue to maintain our help to those in need. Please give generously once more.

Contributions may be passed direct to the treasurer or medical representative of the loca Guilds of the Royal Medical Benevolent Fund or sent, marked "Christmas Appeal," to the Director, Royal Medical Benevolent Fund, 24 King's Road, Wimbledon, London SW19 8QN.

London SW19

T Holmes SELloRs President Royal Medical Benevolent Fund

\section{Points}

\section{Metoclopramide in young children}

Dr A BLoch (Afridar-Ashkelon, Israel) writes: Drs J A Sills and E J Glass have again drawn attention (5 August, p 431) to the care necessary in prescribing metoclopramide for young children. The toxic effects they describe can occur even with normal dosage, ${ }^{1}$ but there is an additional danger which should be stressed in view of the frequent and successful use of this drug for the symptomatic relief of vomiting. I have detailed ${ }^{2}$ the clinical course in three infants aged 8 months, $2 \frac{1}{2}$ years, and 7 months respectively who were each given an intramuscular injection of $5-7.5 \mathrm{mg}$ of metoclopramide for the symptomatic relief of their acute vomiting which, with high fever of one day's duration, was the presenting symptom of their illness. The resultant cessation of their vomiting masked the real diagnosis of Haemophilus influenzae meningitis in the first two and meningococcal meningitis in the third. . . . Casteels-van Daele et $a l^{1}$ have stressed that metoclopramide should be used only after careful consideration. This should include, in my judgment, clinical diagnosis first. There are well-known pharmacological indications for the exhibition of this useful drug, but they do not include symptomatic acute vomiting of unknown origin in small children. ...

Casteels-Van Daele, M, et al, Archives of Disease in Bloch, A, Harefuah, 1974, 86, 411

\section{Malignant mesothelioma in gas-mask assemblers}

Dr J S P JonEs (Nottingham) writes: I was interested to read the article by Drs D B Jefferys and J A Vale (26 August, p 607) in which they report two further cases of wartime gas-mask assemblers who developed mesotheliomas. There are certain inaccuracies in this article to which I would like to draw your attention, in order to avoid confusion in the future. In the opening paragraph the word "fibres" should, I think, read "filters." To suggest that charcoal is a fibrous substance could be misleading. The article attributable to me, dated 1968, was a description of six cases of mesothelioma in Nottingham, two of which were in women who assembled gas masks during the second world war. In a later study $^{1}$ we reported 26 deaths due to mesothelioma in the Nottingham gas-mask assemblers, and in addition to these we noted 18 mesotheliomas in the Leyland/Preston factories, while one case in Birmingham had been detected among gas-mask canister assemblers....

\section{Jones, J S P, Pooley, F D, and Smith, P G, in Environ-} Rosenfeld and W Davis, p 117. Lyon, IARC, 1976.

\section{Treatment of heartburn in pregnancy}

Dr J R Clayden (Holmfirth, Huddersfield) writes: In connection with the recent paper by Mr R D Atlay and others (30 September, p 919) I should like to offer a treatment which I have found to be almost $100 \%$ effective in this condition. It simply consists in adding $0.4 \mathrm{ml}$ of chloroform and morphine tincture $B P C$ to the standard $10 \mathrm{ml}$ dose of magnesium trisilicate mixture $B P C$. This seems to work every time and presumably does so by helping to increase sphincter tone (including the sphincter of Oddi) while at the same time neutralising acid in the stomach....

\section{Preinjection skin swabbing}

Dr J A TALLACK (Brentwood, Essex) writes: In his letter regarding the lack of necessity for preinjection skin swabbing (16 September, p 834) Dr T C Dann overstates his case in quoting an anecdote that $\mathrm{Dr} R \mathrm{D}$ Lawrence used to inject himself through his trouser leg. I have no knowledge of the truth or falsity of this anecdote, but I have had the personal experience of arranging the hospital admission of a medical colleague who was a pethidine addict and used to inject himself in this manner. The same evening half a pint of pus was drained from an abscess deep in the lateral part of the thigh.

\section{Asthma in children}

Dr P Newton (Sale, Cheshire) writes: With reference to the letter from Dr N C H Stott (30 September, $p$ 955) on elimination of the house dust mite, in my experience as both a general practitioner and parent, if one eliminates the house dust mite from the child's bedroom and bars the child from housework that is sufficient. There is a dramatic improvement if not a complete disappearance of symptoms. I would only put parents through this ordeal with a positive skin test or a very suggestive clinical history.

\section{Organising an international medical} meeting

Dr Margaret E Elmes (Department of Pathology, Welsh National School of Medicine, Cardiff) writes: With reference to the article by $\mathrm{Mr}$ Ian Capperauld and $\mathrm{Mr} \mathrm{A}$ I S Macpherson (23 September, p 875) could I put in a plea for the abandoning of the term "ladies' programme" at international medical meetings? The social events concerned can easily be included in the overall social programme and the embarrassment caused to male spouses and children who frequently accompany female delegates could be avoided 